\title{
A modified Whitaker test (upper urinary tract videourodynamics) using for evaluating complex upper urinary tract reconstruction surgical effect
}

\author{
Yang Yang", Xinfei Li", Yunxiang Xiao, Xuesong Li, Yuke Chen, Shiliang Wu \\ Department of Urology, Peking University First Hospital Institute of Urology, Peking University National Urological Cancer Center, Beijing, China \\ Contributions: (I) Conception and design: Y Chen, S Wu; (II) Administrative support: X Li, S Wu; (III) Provision of study materials or patients: Y \\ Xiao, X Li; (IV) Collection and assembly of data: Y Yang, X Li; (V) Data analysis and interpretation: Y Yang, X Li; (VI) Manuscript writing: All \\ authors; (VII) Final approval of manuscript: All authors. \\ \#These authors contributed equally to this work. \\ Correspondence to: Yuke Chen; Shiliang Wu. Department of Urology, Peking University First Hospital. Institute of Urology, Peking \\ University, National Urological Cancer Center, No. 8 Xishiku Street, Xicheng District, Beijing 100034, China. Email: yukecc1989@163.com; \\ wushiliangjsh@263.net.
}

Background: To evaluate the feasibility and effect of upper urinary tract videourodynamics in complex reconstructed upper urinary tract.

Methods: From January 2016 to December 2018, patients who underwent complex upper urinary tract reconstruction and received upper urinary tract videourodynamics were included in the study. The modified Whitaker test was performed at 3 months after operation. The relative pelvic pressure was defined as the pelvic pressure minus the bladder pressure. Based on the flow rate, the test was divided into physiological phase and high flow phase. The results of pressure and image were classified into 3 types. Successful nephrostomy removal was defined as no symptoms and improved or stable hydronephrosis.

Results: A total of 12 patients who underwent complex upper urinary tract reconstruction received modified Whitaker test. All tests were successfully completed without adverse reactions. The relative pelvic pressure of 3 patients kept steady near the baseline throughout the examination and was classified into type 1 . The pelvic pressure of 7 patients increased as the perfusion continued, and the relative pressure dropped to relative low level due to the peristalsis of ureter (type 2). The pressure of 2 patients increased along with increasing perfusion speed, and the relative pelvis pressure could easily reach $15 \mathrm{cmH} 2 \mathrm{O}$. The peristalsis of ureter disappeared or appeared very weakly on the video record (type 3). Patients in type 1 (3 cases) and type 2 ( 7 cases) groups were allowed to remove the nephrostomy tube immediately. Patients in type 3 group needed to keep the nephrostomy for close follow up, and the tubes were removed 2 weeks and 4 weeks after the examination, respectively. None of the 12 patients received further treatment for recurrent symptoms and exacerbation of hydronephrosis.

Conclusions: The modified Whitaker test is initially safe and feasible in postoperative evaluation of complex upper urinary tract reconstruction surgery. Detailed results can provide more evidence to judge whether nephrostomy tube could be removed safely.

Keywords: Videourodynamics; upper urinary tract; reconstruction; surgery

Submitted Jul 01, 2020. Accepted for publication Nov 05, 2020.

doi: $10.21037 /$ tau-20-1055

View this article at: http://dx.doi.org/10.21037/tau-20-1055 


\section{Introduction}

Complex upper urinary tract reconstruction operations are challenging for urologists. More importantly, another burning question is that the effect of this kind of procedure is hard to evaluate $(1,2)$. Traditional methods, including contrast-enhanced CT, MRI and ultrasonography, mainly show the shape of the urinary system without allowing for dynamic observation. More difficult to interpret is the dilatation that remains after relief of obstruction. Diuresis renography could show the dynamic transport of urine in the upper urinary tract. The combination of classic image examination and diuresis renography is currently widely used to assess the patency of the upper urinary tract (3).

The upper urinary tract remains at different degrees of dilation for most patients who underwent ureteral reconstructive surgery, which makes it difficult to assess the obstruction (4). Failure to identify upper urinary tract obstruction before removing the nephrostomy tube may result in recurrent flank pain, fever, deterioration of hydronephrosis, impairment of renal function and secondary percutaneous nephrostomy. Video urodynamics can provide information on both dynamic process of urine delivery and functional parameters such as compliance, dynamic morphological changes and contractility. Therefore, video urodynamics is used for multiple lower urinary tract dysfunctions $(5,6)$. However, it is regrettable that upper urinary tract video urodynamics is rarely used for various reasons. The lack of standardized operating procedures and its alleged inconsistent ability to predict the functional outcome make it difficult to popularize. Additionally, unphysiological approach and invasive manipulation for renal pelvis pressure measurement limits its application $(7,8)$.

In this report, we aim to develop a modified Whitaker in assessing the surgical effects of complex upper urinary tract reconstruction and summarize our preliminary experience of this test with 12 patients in a single tertiary center. We present the following article in accordance with the MDAR reporting checklist (available at: http://dx.doi.org/10.21037/ tau-20-1055).

\section{Methods}

\section{Patient selection}

From January 2016 to December 2018, 136 consecutive patients underwent upper urinary tract reconstruction operations. The complex reconstruction was defined as long ureter defects or multiple lesions that can not be treated with stricture resection and anastomosis, and failure of primary surgery that needs secondary reconstruction. Twelve patients who underwent complex reconstruction were assessed by the modified Whitaker test at 3 months after the surgery. Data on patients' characteristics, etiology, laboratory data, imaging studies, surgery information and perioperative data were collected. The study was conducted in accordance with the Declaration of Helsinki (as revised in 2013) and the Harmonized Tripartite Guideline for Good Clinical Practice from the International Conference on Harmonization. This study was reviewed and approved by the Ethics Board of Peking University First Hospital (registration ID:2019-SR-134). All patients enrolled completed the informed consent form.

\section{Procedures}

The patient was positioned supine. The bladder was drained by a $16 \mathrm{~F}$ Foley catheter just before the test. All nephrostomy tubes were placed before the reconstruction operation for draining urine and were maintained after the surgery. The nephrostomy tube was checked to make sure it was unobstructed. Nephrostomy tubes and urinary catheters were connected to the pressure transducer respectively. Then, set the pressure measuring device to zero in vivo.

The diluted X-ray contrast medium was perfused through the water pump. Different from the flow rates suggested by Whitaker (7), the flow rate was initially set at $1 \mathrm{~mL} / \mathrm{min}$ and increased gradually in this study. Based on the flow rate, the test was divided into two phases. In phase 1 , the flow rate was set as the ordinary physiological rate of urine production $(1-3 \mathrm{~mL} / \mathrm{min})$. Normal pelvis morphology is defined as no hydronephrosis in the renal pelvis and calyces. In phase 2, the function of the upper urinary tract was assessed by increasing the flow rate. The termination flow rate was achieved when the patient experienced loin pain, or the level of relative pressure (which was defined as renal pelvis pressure minus bladder pressure) quickly increased by more than $22 \mathrm{cmH}_{2} \mathrm{O}$, or the flow rate reached $25 \mathrm{~mL} / \mathrm{min}$. After the test was finished, the fluid remaining in the renal pelvis was drained.

The pressure was recorded simultaneously from the renal pelvis and the bladder. The X-ray appearances of the urinary tract were recorded at each flow rate (Figure 1). According to the difference in pressure and image, we divided the results of modified Whitaker tests into 3 types. Type 1: the relative renal pelvis pressure remains steady 
X-Ray

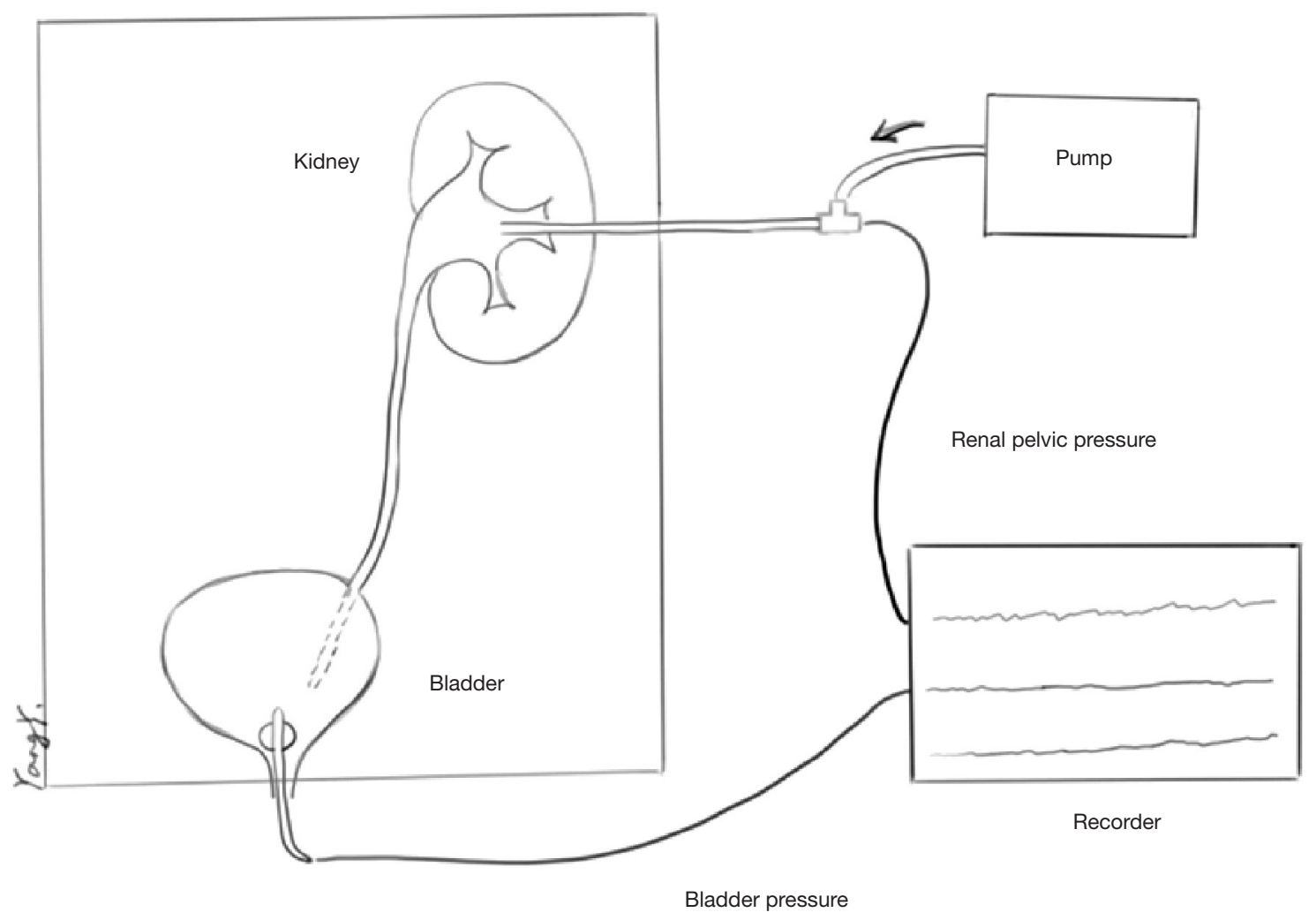

Figure 1 Modified Whitaker test setup.

near baseline, the absolute renal pelvis pressure is below $25 \mathrm{cmH}_{2} \mathrm{O}$, and the reconstructive ureter develops well during the whole examination. Type 2: the relative pelvis pressure increases with the increasing perfusion rate, but the pressure can decrease to a relatively low pressure due to the peristalsis of the ureter. At the end of the test, the relative pelvis pressure is no higher than $15 \mathrm{cmH}_{2} \mathrm{O}$, and the absolute pelvis pressure is not higher than $25 \mathrm{cmH}_{2} \mathrm{O}$. Type 3: the relative pelvis pressure increases with the increasing perfusion rate. At the same time, ureteral peristalsis disappears or is very weak. The relative pelvis pressure can easily exceed $15 \mathrm{cmH}_{2} \mathrm{O}$. Whether to remove the nephrostomy tube referred to the result of modified Whitaker test. Successful nephrostomy removal was defined as no symptoms and improved or stable hydronephrosis.

\section{Statistical analysis}

All analyses were performed with SPSS® Statistics, version 24.0 (IBM Corporation, Somers, NY, USA).

\section{Results}

A total of 12 patients who underwent complex upper urinary tract reconstruction received modified Whitaker test. The characteristics were shown in Table 1. There were 6 males and 6 females. The mean age was 38 years (range, 16-60 years). The reconstructive surgery included ileal ureter replacement, bladder flap replacement of long ureteral stricture and secondary reconstruction. Each of these strategies had 4 patients. All tests were successfully completed without adverse reactions such as fever, severe black pain or extravasation of perfusion fluid.

The results of the modified Whitaker tests in 12 patients were shown in Table 2. In phase 1, six patients (50\%) had a normal pelvic morphology. The pelvis morphology of the other 6 patients showed different degree of hydrops. In phase 2, three patients were classified into type 1 (Figure 2), seven patients were type 2 (Figure 3), and two patients were type 3 (Figure 4). Nephrostomy tubes of patients with type 1 and type 2 were removed immediately after the examination. Type 3 patients maintained the nephrostomy 
Table 1 General information table

\begin{tabular}{|c|c|c|c|c|c|c|c|c|}
\hline Pt. & Age & Sex & Operation & \multicolumn{2}{|l|}{ Outcome } & $\begin{array}{l}\text { Maximum perfusion } \\
\text { rate }(\mathrm{mL} / \mathrm{min})\end{array}$ & $\begin{array}{l}\text { Follow-up } \\
\text { time/months }\end{array}$ & Follow-up \\
\hline 1 & 54 & $\mathrm{~F}$ & Ileal replacement of the ureter & $A b$ & Type 1 & 25 & 20 & No intervention \\
\hline 2 & 48 & M & $\begin{array}{l}\text { Bladder flap replacement of long } \\
\text { ureteral stricture }\end{array}$ & $A b$ & Type 2 & 25 & 18 & No intervention \\
\hline 4 & 39 & $\mathrm{~F}$ & Ileal replacement of the ureter & $\mathrm{N}$ & Type 2 & 25 & 17 & No intervention \\
\hline 5 & 41 & $\mathrm{~F}$ & $\begin{array}{l}\text { Bladder flap replacement of long } \\
\text { ureteral stricture }\end{array}$ & $A b$ & Type 3 & 25 & 14 & No intervention \\
\hline 6 & 28 & M & Reoperation of ureter stricture & $\mathrm{N}$ & Type 2 & 20 & 15 & No intervention \\
\hline 9 & 55 & M & Ileal replacement of the ureter & $\mathrm{N}$ & Type 2 & 20 & 14 & No intervention \\
\hline 10 & 37 & $\mathrm{~F}$ & Reoperation of the UPJO & $\mathrm{Ab}$ & Type 2 & 20 & 14 & No intervention \\
\hline 11 & 21 & M & $\begin{array}{l}\text { Reoperation of the UPJO and ureter } \\
\text { stricture }\end{array}$ & $\mathrm{Ab}$ & Type 3 & 20 & 14 & No intervention \\
\hline 12 & 56 & M & Ileal replacement of the ureter & $\mathrm{N}$ & Type 1 & 25 & 13 & No intervention \\
\hline
\end{tabular}

$\mathrm{N}$, normal pelvic morphology; Ab, abnormal pelvic morphology.

Table 2 Results of videourodynamics

\begin{tabular}{|c|c|c|c|c|}
\hline Videourodynamic diagnosis & $\mathrm{N}$ & $\begin{array}{l}\text { Ileal replacement } \\
\text { of the ureter }\end{array}$ & $\begin{array}{l}\text { Reoperation of the } \\
\text { UPJO or ureter stricture }\end{array}$ & $\begin{array}{l}\text { Bladder flap replacement } \\
\text { of long ureteral stricture }\end{array}$ \\
\hline \multicolumn{5}{|l|}{ Phrase 1} \\
\hline Abnormal pelvic morphology & 6 & 1 & 2 & 3 \\
\hline \multicolumn{5}{|l|}{ Phrase 2} \\
\hline Type 2 & 7 & 2 & 3 & 2 \\
\hline Type 3 & 2 & 0 & 1 & 1 \\
\hline
\end{tabular}

tube to facilitate subsequent treatment.

Due to poor urodynamic results, 2 patients with type 3 maintained the nephrostomy tube after the test. The nephrostomy tubes of both patients were clamped on the second day after the examination. During a close followup, it was confirmed that these 2 patients had no symptoms and hydronephrosis remained stable on B-ultrasound, and the tube was removed 2 weeks and 4 weeks after the examination. None of the 12 patients in this study received further treatment for recurrent symptoms and exacerbation of hydronephrosis.

\section{Discussion}

The Whitaker test was developed by Roger H. Whitaker in the late 1960s (7). This was a groundbreaking test that 

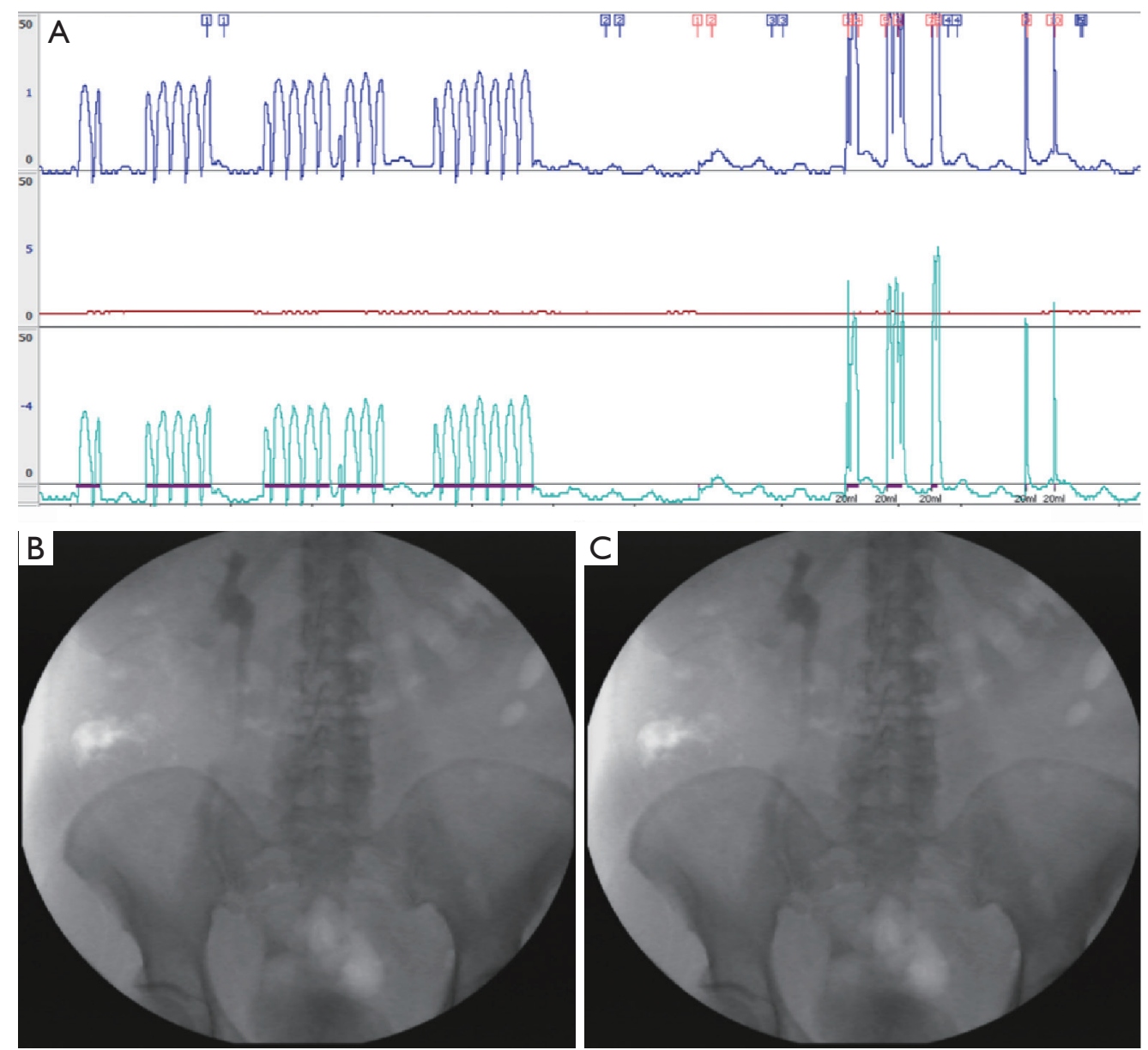

Figure 2 Type 1 modified Whitaker test. (A) Type 1: During the entire process of the test, the relative pelvis pressure remained stable at baseline (the blue line represents pressure in the pelvis, the red line represents pressure in the bladder, and the green line represents relative pelvis pressure). (B) In the phrase 1, the pelvic morphology was normal. (C) In the phrase 2, the peristalsis of the ureter was good.

combined an urodynamic study with antegrade pyelography to measure the pressure of both renal pelvis and bladder. This test was used to help determine whether there was an obstruction in the upper urinary tract. Although the application of the Whitaker test has been debated over half a century, the value is undeniable. Especially for ambiguous upper urinary tract obstruction, traditional examination such as pyelography and/or diuretic renography can not provide a clear judgment. Currently published reports have focused on the application of the Whitaker test in the evaluation of upper urinary tract dilation and ambiguous obstruction in patients without a history of surgery (9-11). It is well known that varying degrees of hydronephrosis persist after upper urinary tract reconstruction surgery (4). There is currently no research on the function of the upper urinary tract after reconstructive surgery. This article is the first report of the use of the Whitaker test in Chinese patients after upper urinary tract reconstruction surgery.

In the present study, some modifications to the Whitaker test were implemented. Assessment of renal pelvis morphology was not included in the classic Whitaker test. The description of the renal pelvis morphology helps to make an initial assessment of the state of the upper urinary tract since the renal pelvis morphology varies. The comparison of the degree of hydronephrosis after surgery and before surgery is often used as a method to evaluate the success of ileal ureteric replacement and ureteropelvic junction obstruction (UPJO) surgery $(12,13)$. Previous studies have reported that renal pelvis morphology under intravenous pyelography (IVP) can be divided into 5 types 

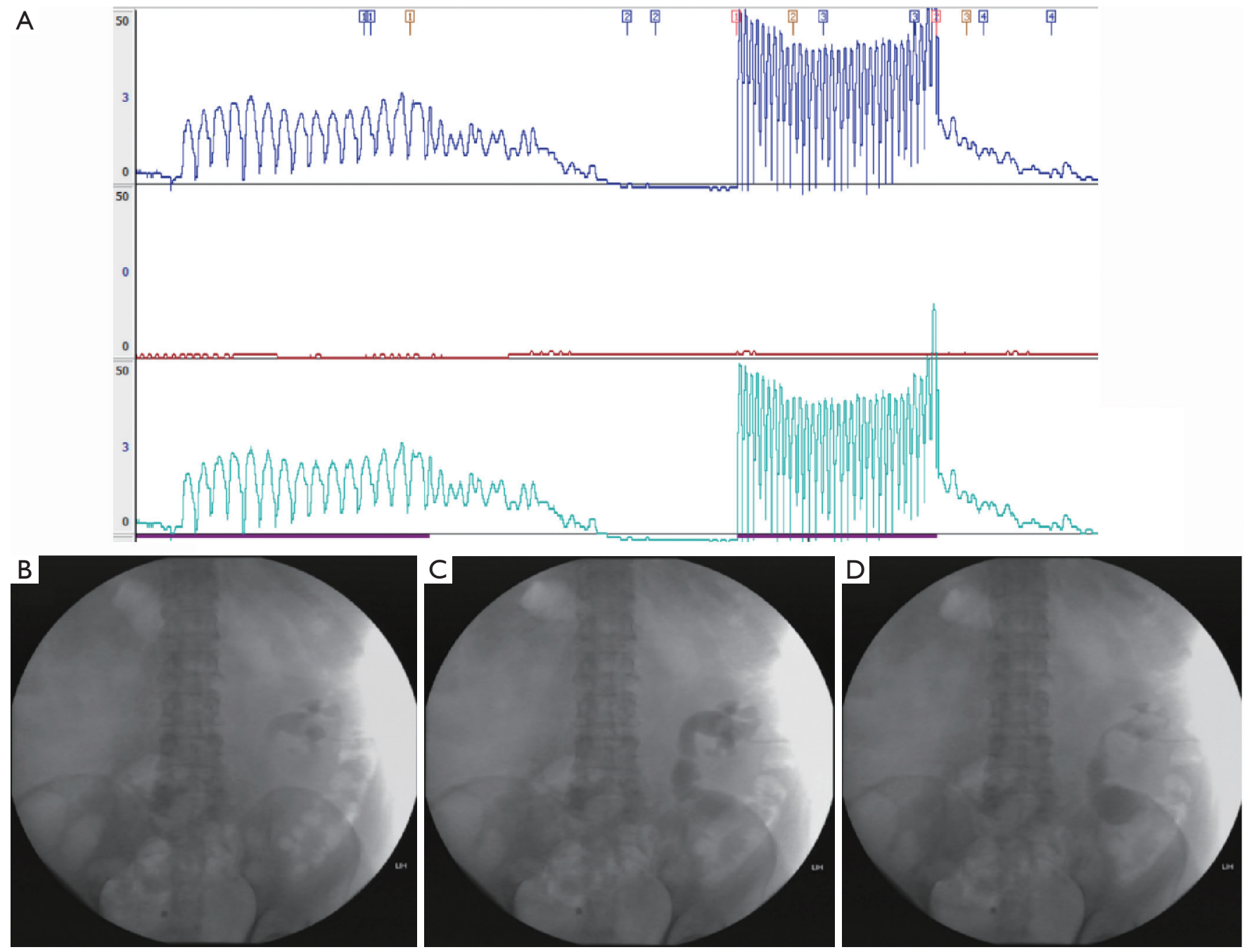

Figure 3 Type 2 modified Whitaker test. (A) Type 2: With peristalsis of the ureter, relative renal pelvis pressure decreased to near baseline. (B) In the phrase 1, the pelvic morphology was unnormal. (C\&D) Showing a peristalsis of the ureter.

to describe the degree of hydronephrosis. Changes in renal pelvis morphology under IVP were used as a method to evaluate the effect of UPJO surgery (14). In this study, the assessment of renal pelvis morphology at the physiological rate of urine production was added in an attempt to evaluate the state of the upper urinary tract more comprehensively.

Another difference from the traditional Whitaker test is the perfusion rate. In the classic Whitaker test, the perfusion rate was constant at $10 \mathrm{~mL} / \mathrm{min}$, which came from healthy volunteers. Because $10 \mathrm{~mL}$ per minute was considered close to the physiological maximum urine production rate (7). Therefore, the classic Whitaker test was theoretically performed in the physiological range. However, this fixed perfusion rate has since been questioned by several studies $(15,16)$. In some specific physiological conditions, the urine output of a single kidney could easily exceed $10 \mathrm{~mL} / \mathrm{min}$. In addition, Lupton $e$ al. suggested that a higher perfusion rate $(12-20 \mathrm{~mL} / \mathrm{min})$ was necessary to unmask some obstructions (15). At the traditional perfusion rate, patients would have been classified into the nonobstructive group, but at higher perfusion rates, the relative pelvis pressure would exceed $22 \mathrm{cmH}_{2} \mathrm{O}$. The ratio was as high as $32.1 \%(9 / 28)$. Further examples showed that these patients with obstruction still needed further treatment to avoid deterioration of renal function (15). Some researchers believed that perfusion at up to $20 \mathrm{~mL} / \mathrm{min}$ could diagnose so-called high-output obstruction. Others, while recognizing this phenomenon, doubted its clinical 


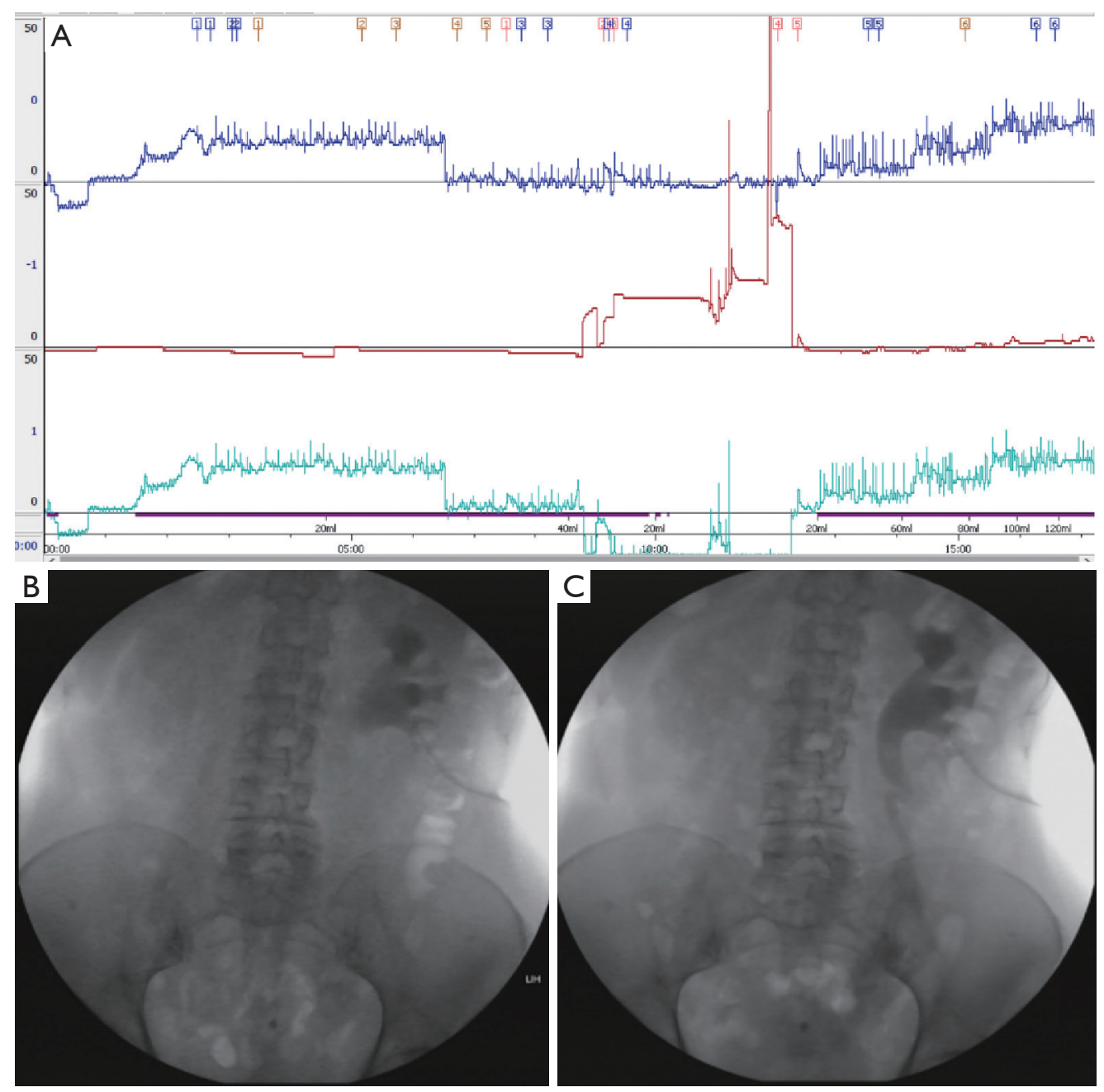

Figure 4 Type 3 modified Whitaker test. (A) Type 3: Relative pelvis pressure increased with increasing perfusion rate. Ureteral peristalsis was weak. Relative pelvis pressure exceeded $15 \mathrm{cmH} 2 \mathrm{O}$. (B) In the phrase 1, the pelvic morphology was unnormal. (C) In the phrase 2, ureteral peristalsis was weak.

significance (17).

In this study, the perfusion rate gradually increased. The initial perfusion rate was $1-3 \mathrm{~mL} / \mathrm{min}$. This speed continued until the renal pelvis could be visualized on the $\mathrm{X}$-ray. The perfusion rate was then increased to $10 \mathrm{~mL} / \mathrm{min}$. The classic perfusion rate lasted until the entire upper urinary tract was filled, which usually needed 5-10 min. After that, the perfusion rate gradually increased to 20 $25 \mathrm{~mL} / \mathrm{min}$ to determine whether there was a high flow obstruction. Upon the appearance of low-back pain, relative pelvis pressure exceeding $22 \mathrm{cmH}_{2} \mathrm{O}$, or absolute pelvis pressure exceeding $25 \mathrm{cmH}_{2} \mathrm{O}$, the perfusion rate did not increase further. Ten of twelve patients in this study had a maximum perfusion rate of $20 \mathrm{~mL} / \mathrm{min}$ or more. No highflow obstruction was found.

Both type 1 and type 2 patients in this study belonged to the non-obstructive group in the traditional Whitaker test. However, we found some interesting differences. Type 1 is interpreted as a super unobstructed type, and the relative pelvis pressure is maintained at the baseline level even under conditions of high-speed perfusion. Type 2 is interpreted as a general unobstructed type. The relative pelvis pressure in this type of patient will increase with perfusion, even exceeding $15 \mathrm{cmH}_{2} \mathrm{O}$, but with strong peristalsis of the ureter, the pressure will drop to close to the baseline level. This phenomenon is most typical in 
ileal replacement of ureter cases. Type 3 patients belong to the equivocal obstruction group in the classical Whitaker test. Although the relative pelvis pressure does not reach $22 \mathrm{cmH}_{2} \mathrm{O}$ under conditions of high-speed perfusion, the ureteral peristalsis of patients in this group weakens or disappears, suggesting that close follow-up is needed afterwards. The renal pelvis typically holds $3-10 \mathrm{~mL}$ of urine (18). The accuracy of the Whitaker test will reduce in patients with severe hydronephrosis who had a renal pelvis volume of more than $70 \mathrm{~mL}$ (17). This may explain why the two patients belonging to the type 3 group in this article also had their nephrostomy tube safely removed and why the hydronephrosis remained stable during follow-up. However, patients of this type still need close follow-up to determine whether poor upper urinary tract motility causes damage to renal function.

Overall, the patients in this study had good results after upper urinary tract reconstruction, and there were no patients with clear upper urinary tract obstruction. The results of the modified Whitaker test are consistent with good follow-up results.

An important factor that has long influenced the clinical application of the Whitaker test is that the test is invasive. Patients had to undergo a percutaneous nephrostomy for this test. A 25-year summary of experience reported that immediate testing was not recommended after indwelling nephrostomy tubes. Because the kidney status was unstable, it would affect the accuracy of the test results. Patients needed to have a nephrostomy tube 3-7 days before the test to obtain reliable results (9). This would undoubtedly bring more inconvenience to the living conditions of patients. In the present study, patients did not need to undergo more invasive procedures. This is a clear advantage of the Whitaker test in postoperative patients. These patients have a relatively long indwelling nephrostomy tube after surgery. It is necessary to pay attention to the occurrence of local infection and blockage of nephrostomy tubes before the examination.

This study is a preliminary discussion of the Whitaker test applied to patients after complex upper urinary tract reconstruction surgery and has many limitations. The first was the small sample size, which made comprehensive classification difficult. Second, all the patients enrolled in this study had undergone upper urinary tract reconstruction. Compared with patients who had not undergone surgery, the influencing factors were more numerous. In addition, the lack of controlled examination methods was also a deficiency of this study. Follow-up studies need to expand the number of cases, and studies for specific surgical methods need to be further carried out.

In conclusion, the modified Whitaker test is safe and feasible in postoperative evaluation of complex upper urinary tract reconstruction surgery. Detailed results can provide more evidence to judge whether nephrostomy tube could be removed safely. Large samples and long term follow-up result are necessary for verification of this modified procedure.

\section{Acknowledgments}

Funding: This work was supported by Grants the Peking University Medicine Fund of Fostering Young Scholars' Scientific \& Technological Innovation to Yuke Chen (Grant No. BMU2018PYB002).

\section{Footnote}

Reporting Checklist: The authors have completed the MDAR reporting checklist. Available at http://dx.doi.org/10.21037/ tau-20-1055

Data Sharing Statement: Available at http://dx.doi. org/10.21037/tau-20-1055

Conflicts of Interest: All authors have completed the ICMJE uniform disclosure form (available at http://dx.doi. org/10.21037/tau-20-1055). XL has served as an unpaid editorial board member of Translational Andrology and Urology since March 2012. The authors have no other conflicts of interest to declare.

Ethical Statement: The authors are accountable for all aspects of the work in ensuring that questions related to the accuracy or integrity of any part of the work are appropriately investigated and resolved. The study was conducted in accordance with the Declaration of Helsinki (as revised in 2013) and the Harmonized Tripartite Guideline for Good Clinical Practice from the International Conference on Harmonization. This study was reviewed and approved by the Ethics Board of Peking University First Hospital (registration ID: 2019-SR-134). All patients enrolled completed the informed consent form.

Open Access Statement: This is an Open Access article distributed in accordance with the Creative Commons Attribution-NonCommercial-NoDerivs 4.0 International License (CC BY-NC-ND 4.0), which permits the non- 
commercial replication and distribution of the article with the strict proviso that no changes or edits are made and the original work is properly cited (including links to both the formal publication through the relevant DOI and the license). See: https://creativecommons.org/licenses/by-nc-nd/4.0/.

\section{References}

1. Shopfner CE. Non-obstructive hydronephrosis and hydroureter. Am J Roentgenol Radium Ther Nucl Med 1966;98:172-80.

2. Farrugia MK, Whitaker RH. The search for the definition, etiology, and effective diagnosis of upper urinary tract obstruction: the Whitaker test then and now. J Pediatr Urol 2019;15:18-26.

3. Donald BM, Diego DP, Andrew T, et al. The SNMMI and EANM practice guideline for renal scintigraphy in adults. Eur J Nucl Med Mol I 2018;45:1-11.

4. Koff S Whitaker RH. The search for the definition and effective diagnosis of upper urinary tract obstruction: the Whitaker test then and now. J Pediatr Urol 2019;15:27-8.

5. Barton EJ, Sherwood T. Video urodynamic studies and clinical outcome. Brit J Radiol 1983;56:805.

6. Spinoit, AF, Decalf V, Ragolle I, et al. Urodynamic studies in children: Standardized transurethral video-urodynamic evaluation. J Pediatr Urol 2016;12:67-8.

7. Whitaker RH. Methods of accessing obstruction in dilated ureters. Br J Urol 1973;45:15-22.

8. O'Reilly PH. Current status of diuretic renography. In Freeman LM Weissmann HS eds, Nuclear Medicine Annual New York: Raven Press, 1987:173-92.

9. Lupton EW, George NJ. The Whitaker test: 35 years on.

Cite this article as: Yang Y, Li X, Xiao Y, Li X, Chen Y, Wu S. A modified Whitaker test (upper urinary tract videourodynamics) using for evaluating complex upper urinary tract reconstruction surgical effect. Transl Androl Urol 2021;10(1):336-344. doi: 10.21037/tau-20-1055
BJU Int 2010;105:94-100.

10. Lovasz S, Lovasz L, Nyirady P, et al. A novel quantitative method for measuring obstruction in the upper urinary tract: The obstruction coefficient. Int J Urol 2008;15:499504.

11. Radomski SB, Moran ME, Stone AR. Upper urinary tract videourodynamics: a more complete Whitaker test. Can J Urol 1995;2:154-8.

12. Kocot A, Kalogirou C, Vergho D, et al. Long-term results of ileal ureteric replacement: a 25-year single-centre experience. BJU Int 2017;120:273-9.

13. Krajewski W, Wojciechowska J, Dembowski J, et al. Hydronephrosis in the course of ureteropelvic junction obstruction: An underestimated problem? Current opinions on the pathogenesis, diagnosis and treatment. Adv Clin Exp Med 2017;26:857-64.

14. Esa A, Sugiyama T, Park YC, et al. Evaluation of pyeloplasty: a comparison of radio-morphology, pressure flow study and diuresis renography of the upper urinary tract. Percutaneous pyelolysis for uretero-pelvic junction obstruction: a case report. Nihon Hinyokika Gakkai Zasshi 1987;78:2161-7.

15. Lupton EW, Holden D, George NJ, et al. Pressure changes in the dilated upper urinary tract on perfusion at varying flow rates. Br J Urol 1985;57:622-4.

16. Pfister RC, Newhouse JH, Hendren WH. Percutaneous pyeloureteral urodynamics. Urol Clin North Am 1982;9:41-9.

17. Johnston RB, Porter C. The Whitaker test. Urol J 2014;11:1727-30.

18. Alan JW. CAMPBELL-WALSH Urology 11th Ed. Philadelphia: Elsevier, 2016. 